\title{
Editorial
}

\section{My Career as a Mineral Physicist at Stony Brook: 1976-2019}

\section{Robert Cooper Liebermann 1}

Mineral Physics Institute and Department of Geosciences, Stony Brook University, Stony Brook, NY 11794-2100, USA; Robert.Liebermann@stonybrook.edu; Tel.: +001-(631)-766-5711

Received: 14 November 2019; Accepted: 6 December 2019; Published: 7 December 2019

\begin{abstract}
In 1976, I took up a faculty position in the Department of Geosciences of Stony Brook University. Over the next half century, in collaboration with graduate students from the U.S., China and Russia and postdoctoral colleagues from Australia, France and Japan, we pursued studies of the elastic properties of minerals (and their structural analogues) at high pressures and temperatures. In the 1980s, together with Donald Weidner, we established the Stony Brook High Pressure Laboratory and the Mineral Physics Institute. In 1991, in collaboration with Alexandra Navrotsky at Princeton University and Charles Prewitt at the Geophysical Laboratory, we founded the NSF Science and Technology Center for High Pressure Research.
\end{abstract}

Keywords: mineral physics; ultrasonic interferometry; high-pressure multi-anvil apparatus; synchrotron X-radiation; CHiPR (Center for High Pressure Research); COMPRES (Consortium for Materials Properties Research in Earth Sciences); Stony Brook University

\section{Introduction}

In March 2013, I was invited by Tetsuo Irifune to give the keynote address at the Final Symposium of G-COE and TANDEM program at Ehime University in Matsuyama, Japan. I chose that opportunity to reflect on my career in mineral physics with the title: "Mineral Physics and Bob-san from 1963 to 2013: Role of Serendipity." Yanbin Wang was in the audience in Matsuyama and suggested that I submit a manuscript on this topic to Physics of the Earth and Planetary Interiors for a Special Issue for which he was the Guest Editor. When Jay Bass heard of this talk, he recommended that I be asked to reprise this talk after the banquet at the 2013 Annual Meeting of COMPRES at Lake Geneva, Wisconsin in June 2013; I modified the title for the U.S. audience: "Role of Serendipity in My Career in Mineral Physics: 1963 to 2013." In October 2013, Dan Davis (the Chair of the Department of Geosciences) invited me to give this talk at the weekly Geosciences Colloquium and later to adapt it for the Geosciences Newsletter. This paper is the result and focuses on my career in mineral physics at Stony Brook from 1976 to 2019 and it compliments my earlier paper in Physics of the Earth and Planetary Interiors [1].

\section{Before Stony Brook}

After being an undergraduate in geophysics at Caltech and obtaining a $\mathrm{PhD}$ at Columbia University under Orson Anderson, I spent 6 years at the Australian National University (ANU) in Canberra working in the high-pressure laboratory of Ted Ringwood. When I decided to explore the opportunities to return to the U.S. to a tenure-track faculty position, I was fortunate that the Department of Earth and Space Sciences at Stony Brook was conducting a faculty search led by Don Weidner, who was open-minded enough to consider hiring another mineral physicist. I was encouraged to negotiate an attractive start-up package by Charlie Prewitt and Ted Bence (who were on sabbaticals in Australia at Monash University in Melbourne and the ANU, respectively). 


\section{Start of my Career at Stony Brook (1976 to 1983)}

I arrived in December 1976, shortly after the birth of our third child (two of whom are Australians) and was welcomed by the faculty, graduate students, and staff. Several of the senior graduate students of Prewitt and Weidner (Alan Kafka, Hubert King, Louise Levien, and Mike Vaughan) took me under their wing and "taught" me how to become a faculty member.

When the Provost Sei Sujishi learned that my first proposal to NSF Geophysics (which I wrote while still in Canberra) had been approved for funding, he immediately freed up the start-up funds which enable me to place an order for a 500-ton hydraulic press from Harwood Engineering and a girdle-anvil, high-pressure apparatus from Pressure Systems Research. This equipment was delivered in September 1977 and installed in Room 375 of the ESS Building with the help of Tony Vidmar (our new technician), Al Catalano (machinist) and Alan Major (consultant from Ringwood's lab at the ANU) (see Figure 1a,b). Vidmar and I had been flown in Fred Gwinner's plane to Boston to visit the Harwood factory to assess the needs for installing the new press (Fred was foreman of the departmental Machine Shop). On our return to campus, we had to educate the Facilities and Engineering unit at Stony Brook about the difference between weight/force and pressure, as they were nervous about installing such a heavy press on the third floor of the Earth and Space Sciences Building.

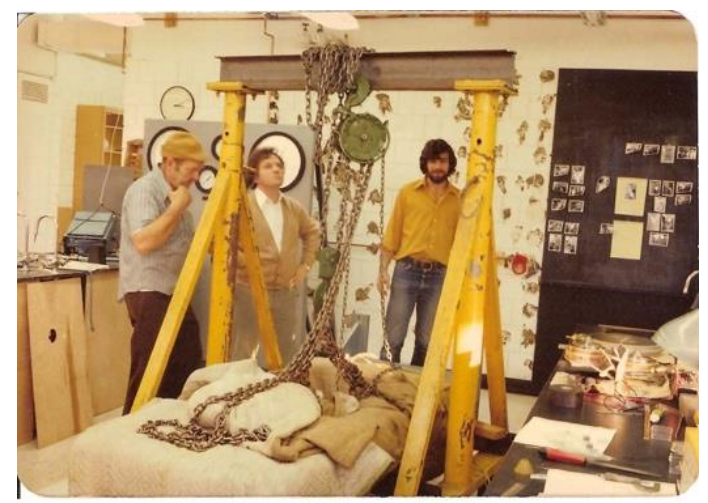

(a)

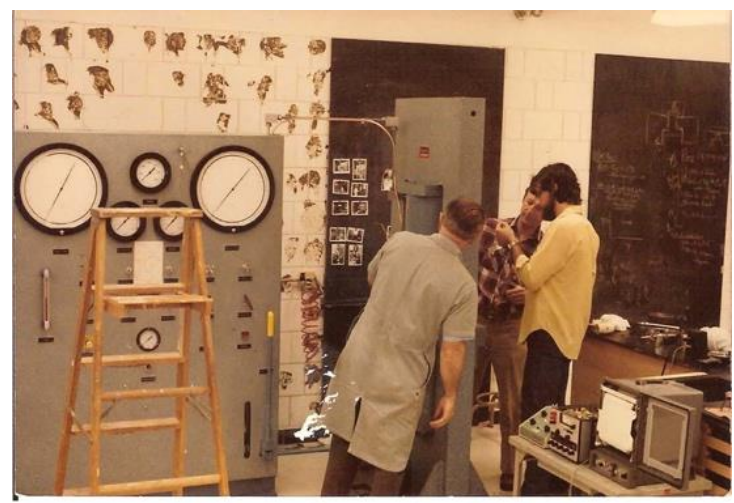

(b)

Figure 1. Installation of Harwood 500-ton press and girdle-anvil apparatus in 1977. (a) Bob and technician Tony Vidmar contemplating how to bring the press to upright position; (b) Al Catalano (machinist extraordinaire) and Alan Major from ANU with Tony Vidmar checking hydraulic connections to press.

In Spring 1977, I served on the Graduate Committee and had a chance to get an early look at the applications for Fall 1977. We were successful in recruiting Paula Davidson from Brown University, with lobbying from Louise Levien and as the result of a return visit to campus by Paula. From my colleagues Charlie Sclar at Lehigh University and Taro Takahashi at Queens College of CUNY, I learned that Jay Bass was unhappy at Arizona State University and looking for a new institution to continue his Ph.D. studies. I contacted Jay and invited him to apply to our Department, which he did and arrived in August 1977 with Paula. Although both Paula and Jay ultimately decided to pursue their doctoral dissertations under the supervision of other Earth Science faculty (Don Lindsley for Paula and Don Weidner for Jay), I have always taken a special pride in helping to recruit them to Stony Brook.

My first teaching experience at Stony Brook was in the Spring 1977 semester, in which I offered ESS 607: Topics in Geophysics; I chose to adapt my informal lectures on "solid-state geophysics" from the ANU and enjoyed having Robin Reichlin and Doug Anderson in the class (along with Kafka, King, Levien and Vaughan who sat in for moral support). This course was modeled after one I took from Orson Anderson at Columbia in the 1960s (and which later evolved into his book "Equations of State of Solids for Geophysics and Ceramic Science" [2]). In Spring 1978, this course was approved as ESS 556: Solid State Geophysics; over the next 35 years, I have taught this course another 13 times and profited from having an outstanding series of geophysics and geochemistry graduate students enroll (see list of 
these students below Appendix A). I have also taught a shortened versions in France at the Université Paris XI in Orsay in 1983 and at the Université Paul Sabatier in Toulouse in 2002 (where is had been incorporated as a foundation course for their Master's students and it now taught by Frédéric Béjina).

The period of 1976-1983 was an active period of recruiting new faculty in geophysics by Don Weidner and me. We were very fortunate that the strong geochemistry group stepped back and allowed the new geophysics program to reach maturity. During this period, many new geophysics faculty were hired, some of whom stayed to pursue their careers (Teng-fong Wong and Dan Davis) while others moved on to other institutions (Brad Hager, Jay Melosh, Rob Comer, Cliff Thurber). The addition of Wong and Davis expanded the research programs in experimental geophysics while the later appointments of Bill Holt and Lianxing Wen opened up new opportunities in global geodynamics and seismology.

Most significantly, Ann Lattimore joined the group as an Administrative Assistant in the mineral physics group in the early 1980s and served with distinction for the next 25 years until her retirement in 2007 (see Figure 2 from her retirement party).

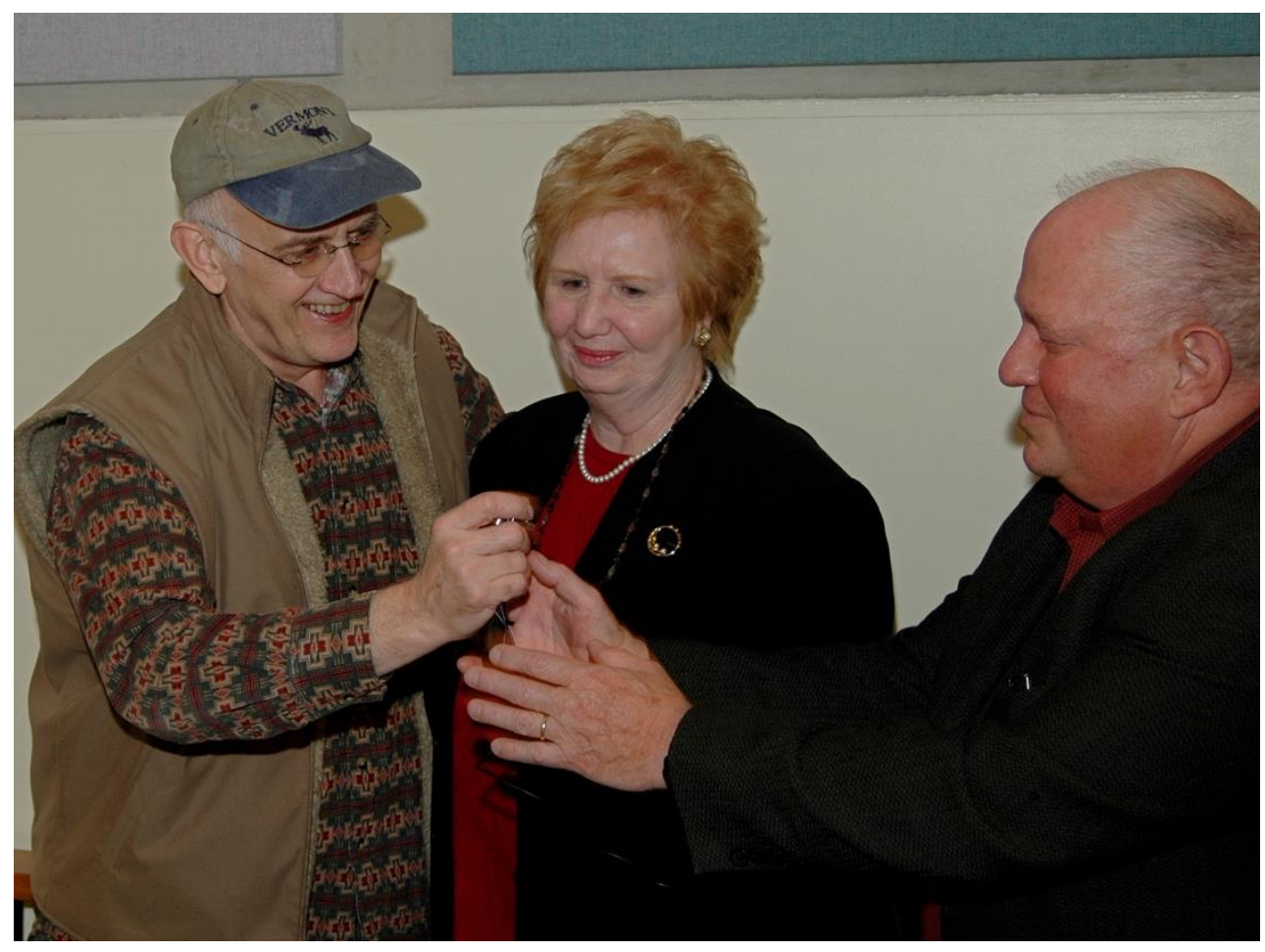

Figure 2. Ann Lattimore with Don Weidner and Bob on occasion of her retirement in 2007.

While my own research laboratory was in its infancy, I profited by collaboration with a series of visiting scientists who came to the Brillouin spectroscopy laboratory of Don Weidner to measure the elasticity of single crystal of mantle minerals which they had synthesized in their home laboratories, including Eiji Ito, Hiroshi Sawamoto, Nozumu Hamaya and Akira Fukizawa. When Don published his new elastic moduli of single-crystal $\mathrm{SiO}_{2}$-coesite [3], he included ultrasonic sound velocity data which I had obtained on a polycrystalline specimen at the ANU. As his first research project at Stony Brook, Jay Bass engaged a junior faculty member in the Department of Applied Mathematics in an investigation to obtain the elastic properties of minerals from joint inversion of data from acoustic and static compression experiments [4].

My first graduate student at Stony Brook, Barbara Leitner, synthesized a single crystal of pyrope garnet in Don Lindsley's petrology lab and measured its elastic properties in Weidner's Brillouin lab for her M.S. thesis project [5]. In collaboration with Charlie Prewitt and his postdoc Satoshi Sasaki, we documented the crystal structure of $\mathrm{CaGeO}_{3}$-perovskite using a specimen synthesized in my lab at the ANU [6]. 
During this same period, Susan Narbut and Ann Sirinides completed their M.S. theses in my laboratory on the elasticity of two-phase aggregates produced by phase transformations involving disproportionation reactions. A separate project on attenuation and dispersion in anelastic materials pursued by Ann Singer was not successful; however, during my sabbatical in France in 1983-1984 supported by a grant from the NSF, I published a theoretical paper with Jean-Paul Poirier on the activation volume for creep and its variation with depth in the Earth's lower mantle [7].

In addition to the undergraduate students cited below, two students obtained B.S. Honors thesis under my supervision: Peter Lellis worked on isostructural systematics of elasticity in mantle minerals and Kirk Maasch evaluated data from acoustic and static compression experiments on the elastic behavior of hematite [8].

In 1979, the National Research Council of the U.S. National Academy of Sciences commissioned a study of "The Impact of Technology on Geophysics." I was invited to prepare and publish a chapter in this study entitled "The impact of technology on high-pressure geophysics [9].

When I visited Stony Brook for an interview for a faculty position in 1976, the Chair Pete Palmer asked me what my plans were for conducting geophysical surveys of Long Island; I think that Pete was disappointed when I told him I had no such plans. However, a few years later, the U.S. Nuclear Regulatory Commission, which was funding a Northeast Seismic Network to monitor local earthquake activity, invited Weidner and me to acquire seismic monitoring equipment and install it on Long Island where the Shoreham nuclear plant was scheduled to open shortly. Over the next 5 years, we operated seismic stations in the Mashomack Preserve on Shelter Island and in the Caumsett State Park on Lloyd's Neck. For their M.S. thesis research, Ellyn Schlesinger conducted a seismic noise survey on Long Island and Richard Wilkinson conducted an intensity survey to confirm the location and focal mechanism of an earthquake which occurred beneath Long Island Sound near Greenport in October 1981. When Neville Carter left for Texas A\&M, Wong and I inherited his liquid pressure system, which led to a M.S. thesis by Tom Ruubel measuring velocities in natural rocks from the Ramapo fault system. While the pursuit of this local seismology project diverted some resources from our other funded projects (including important contributions by Kafka, Leitner and Vaughan), it gave us an opportunity to engage a series of undergraduates in research; these included Emanuel Caiti, Claire Teuten, Linda Gunderson, and Kirk Maasch, as well as Noel Barstow (a structural geology graduate student), Thomas Caruso (a seismology graduate student), Schlesinger, and Wilkinson. We also occupied temporary seismic stations, including one in the Morton Wildlife Refuge on Jessup Neck (only accessible using Mike Vaughan's canoe). One of our helpers in this field work was a paleontology graduate student who insisted that we purchase deer tick collars to protect him from lyme disease.

As described in detail below, the Stony Brook mineral physics team (Liebermann, Prewitt and Weidner) submitted a major instrumentation proposal to the NSF Earth Sciences Division in August 1983 for a new generation of high-pressure apparatus. I then departed for France for a year-long sabbatical leave, my first at Stony Brook. I was lodged at the Université Paris XI in Orsay, outside Paris, with the research group headed by Olivier Jaoul; we commenced a study of atomic diffusion of Fe and $\mathrm{Si}$ in olivine at high pressure [10], which evolved to a 20-year collaboration driven primarily by a series of graduate students and postdocs (Yves Bertran-Alvarez [11,12], Paul Raterron [13], Frédéric Béjina $[14,15])$. As we were not able to transfer our family to Tokyo in January 1984 due to the lack of appropriate accommodation for our "large" family (us and three kids under age 15), we decided to remain in the Paris region and Jean-Paul Poirier generously provided some financial support; this led to a strong collaborative effort between the laboratories of Poirier in Paris and ours in Stony Brook focused using transmission electron microscopy to understand the mechanism of phase transformations in minerals at high pressures (driven by postdocs and visiting scientists Jannick Ingrin [16], James Boland [17], François Guyot [18], Isabelle Martinez [19], Laurence Galoisy (from the laboratory of Georges Calas)) who worked with our graduate students Anne Remsberg [20], Yanbin Wang [21] and Gabriel Gwanmesia [22]. 


\section{Establishment Stony Brook High Pressure Laboratory and Evolution to CHiPR and COMPRES: 1984 to 2019}

In 1971, as I was attending the International Union of Geodesy and Geophysics (IUGG) Congress in Moscow and making an academy exchange visit to Czechoslovakia, Ringwood encouraged me to visit the high-pressure laboratories in Japan enroute back to Canberra. Guided by Naohiro Soga and Mineo Kumazawa, I spent ten days visiting labs in Tokyo, Nagoya, Kyoto and Osaka.

In 1983, the NSF Division of Earth Sciences created a new program for Instrumentation and Facilities. We (Liebermann, Prewitt and Weidner) decided to submit a proposal for a modern, multi-anvil, high-pressure lab modeled on those in Japan. Our proposal was funded in late 1983, we began to consider the options for acquiring high-pressure apparatus for our laboratories at Stony Brook University.

By the mid-1980s, most of the new developments in multi-anvil, high-pressure apparatus had become concentrated in Japan. In summer 1984, we went on a "shopping trip" to companies and laboratories in Japan to search for high pressure equipment, including Tokyo, Tsukuba, Nagoya, and Misasa. We decided to import two different types of high-pressure apparatus to Stony Brook: (1) a DIA-type, cubic-anvil apparatus modeled after MAX-80 at the Photon Factory (PF) in Tsukuba and named SAM-85 (Figure 3a); and (2) a Kawai-type, 2000-ton uniaxial, split-sphere apparatus modeled on the 5000-ton version in the laboratory of Eiji Ito and named USSA-2000 (Figure 3b).

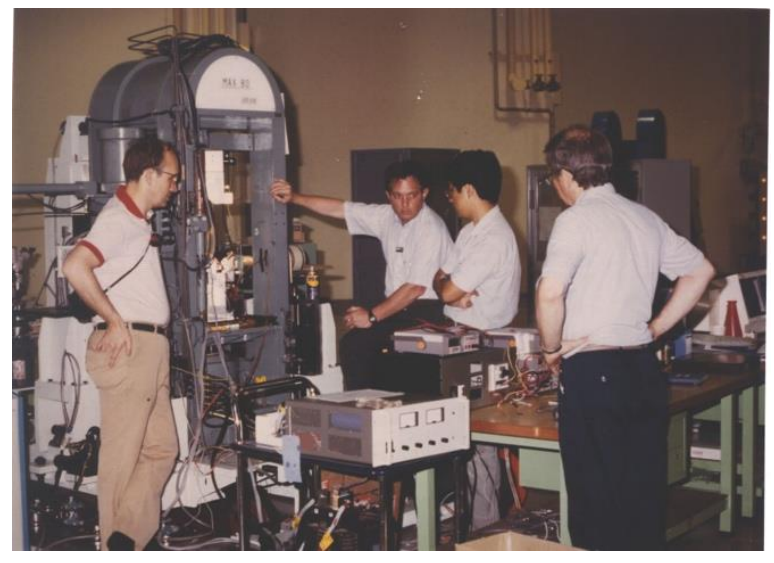

(a)

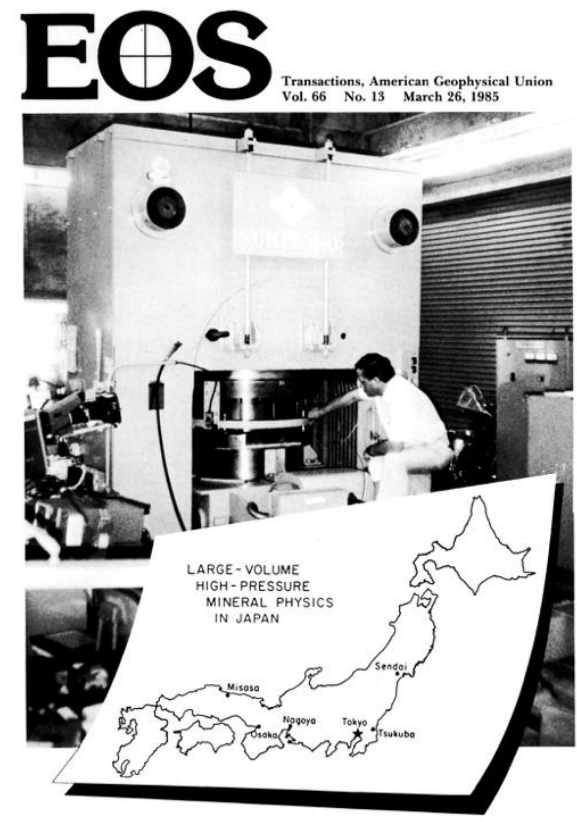

(b)

Figure 3. (a) MAX-80 at Photon Factory in Tsukuba in 1984. Don Weidner, author and Charlie Prewitt with Osamu Shimomura. This modified DIA apparatus was designed by a team led by Osamu Shimomura and Takehiko Yagi and installed on a X-ray beamline at the Photon Factory in Tsukuba, Japan in the early 1980s; it was called MAX-80 for "multi-anvil type X-ray system designed in 1980." (b) Author in laboratory of Eiji Ito in ISEI, Misasa, Japan with USSA-5000 apparatus. This is a Kawai-type, double-stage, multi-anvil apparatus. This USSA-5000 apparatus later served as the model for multi-anvil laboratories at Stony Brook University in the U.S. (Liebermann, Prewitt and Donald Weidner), at the University of Alberta in Canada (Christopher Scarfe), and the Bayerisches Geoinstitut in Germany (David Rubie).

In the summer of 1985, SAM-85 was installed initially in Room 375 with the guidance and assistance of Osamu Shimomura, Yosiko Sato and Hisao Kanda (Figure 4a,b). One of the first experiments in SAM-85 was the synthesis of artificial diamond by Hisao Kanda (see Figure 4c). 


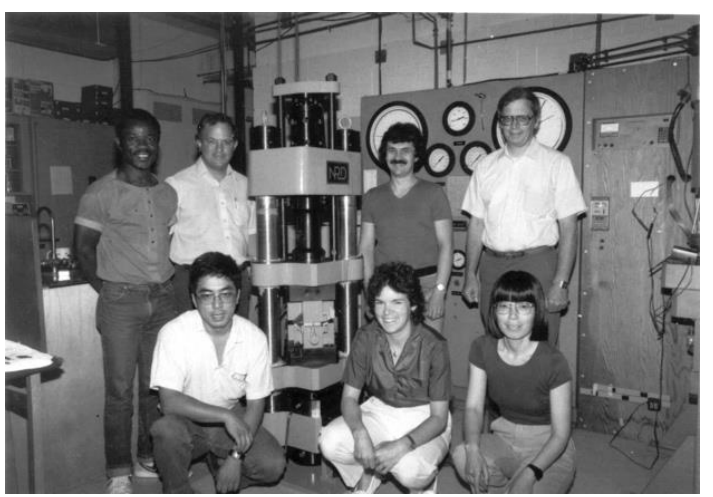

(a)

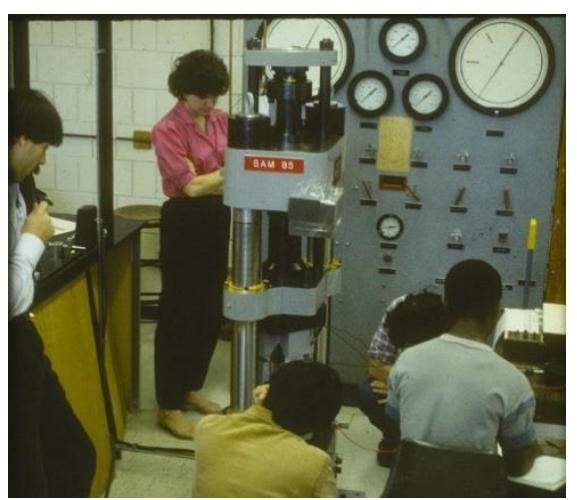

(b)

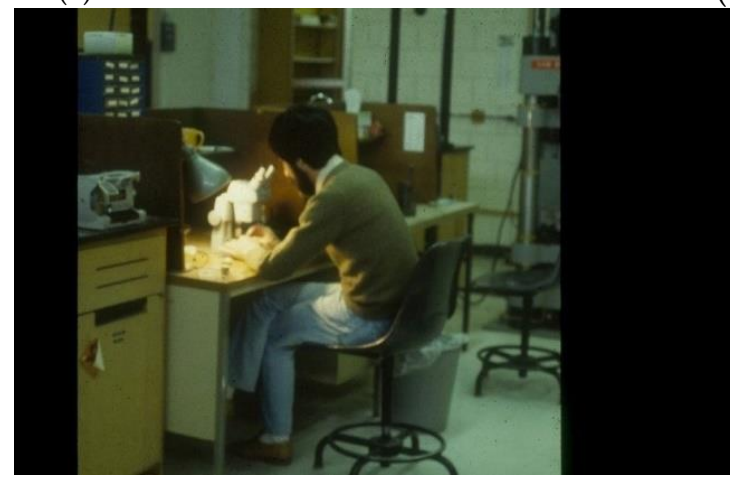

(c)

Figure 4. (a) Team of Gabriel Gwanmesia, Osamu Shimomura, Anne Remsberg, Yosiko Sato, Tibor Gasparik and Charlie Prewitt with author after installation of SAM-85 (Six Anvil Machine named for Osaamu Shimomura and Osamu Fukunaga, who designed the apparatus). Reproduced with permission from Liebermann [1], published by Elsevier B.V., 2014. (b) Consultation among first users of SAM-85: Jannick Ingrin, Anne Remsberg, Hisao Kanda, Tibor Gasparik and Gabriel Gwanmesia. (c) Hisao Kanda preparing to synthesize artificial diamonds for the first time at Stony Brook in SAM-85.

In December 1985, the USSA-2000 apparatus was installed in a new High Pressure Laboratory at Stony Brook (Figure 5a,b). During these installations, we profited from the guidance and advice of many Japanese colleagues (Figure 5c). From 1985 to 2002, Tibor Gasparik (Stony Brook Ph.D., 1981) served as the Manager of the High-Pressure Lab, with Bob as the Director (Figure 5d). The laboratory as it existed in 1985 following the dedication ceremony overseen by the author, Don Weidner and Charlie Prewitt (Figure 6).

During the 1985-1986 year, three Japanese scientists spent 9-12 months each as visitors to the High-Pressure Laboratory: Hisao Kanda from the National Institute for Research in Inorganic Materials in Tsukuba, Manabu Kato from Nagoya University and Hiroshi Watanabe from Osaka University (see photo in Figure 5c). Kanda discovered an unused high-pressure apparatus on the loading dock in the Department of Chemistry at Stony Brook. After some detective work, we learned that this press belonged to William LeNoble in Chemistry, who had inherited it from the U.S. Army Benet Weapons Laboratory in Watervliet, NY. He generously gave us the press and, after a difficult passage across campus when the forklift became stuck in the mud, it was installed in the High-Pressure Laboratory. Our talented machine shop staff refurbished the press and pumping system and Virginia Haniford, one of Don Weidner's graduate students, painted it a bright green (see Figure 7a). This press contained two rams, one of 700 ton capacity and one of 300 ton, and had originally been designed by George Kennedy and Ivan Getting at UCLA. We purchased a Walker-type multi-anvil module, inserted it in this press, and christened it the Uniaxial Split-cylinder Apparatus with 1000 ton rams (USCA-1000).

We also moved the 500-ton Harwood press and SAM-85 to the High-Pressure Lab and Gabriel Gwanmesia conducted pressure calibration experiments on both of them for his M.S. thesis (Figure 7b). 
Thus, by mid-1986, there were four distinct high-pressure systems operational in the High-Pressure Laboratory: the USSA-2000, the Kennedy-Getting press, the Harwood press and SAM- 85 and the lab was fully-equipped and nice and clean (Figure 7c).

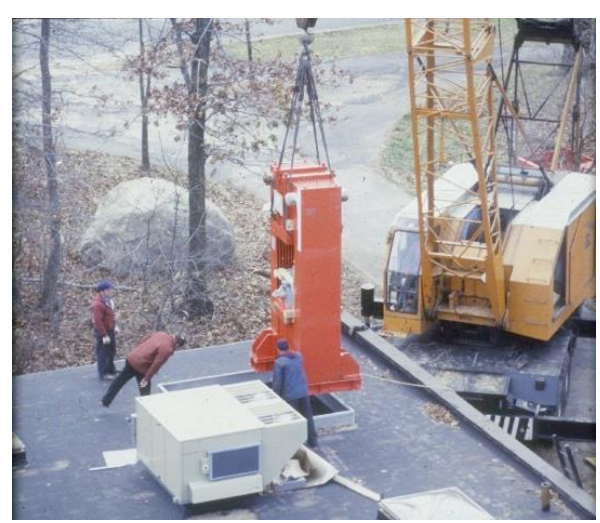

(a)

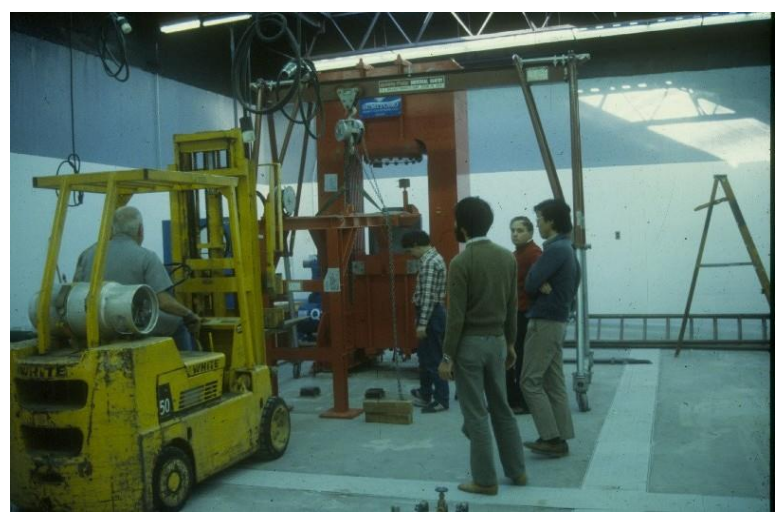

(c)

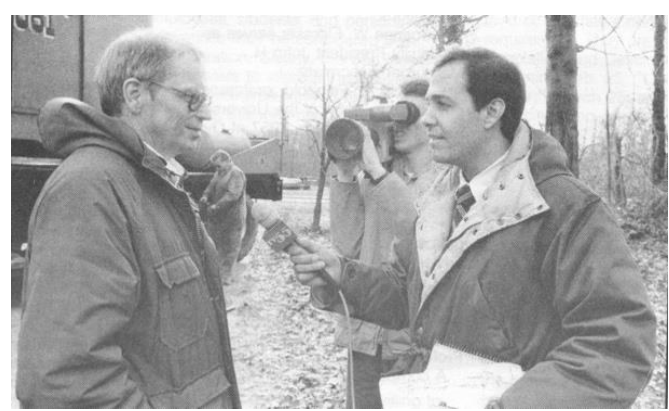

(b)

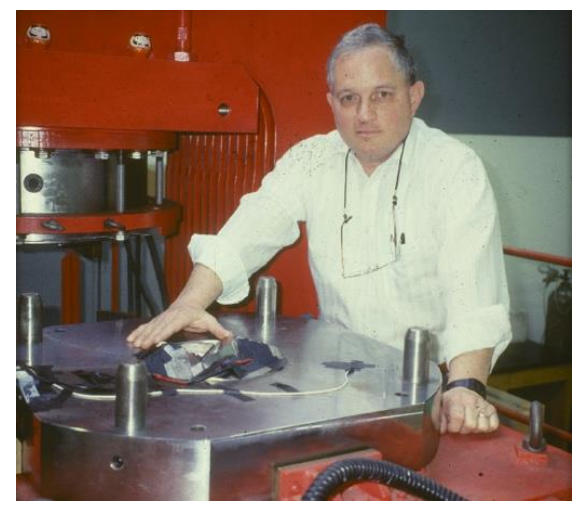

(d)

Figure 5. (a) Installing USSA-2000 in the High-Pressure Laboratory at Stony Brook University in December 1985. This building had originally been a cooling tower and had fallen into disuse. Charlie Prewitt "discovered" it and we were able to convince the university to renovate it to house the new multi-anvil, high-pressure apparatus in 1985. (b) The installation on 4 December 1985 was recorded by Channel 55 News in New York City, who asked us to halt the installation until their cameraman could arrive; this required us to instruct the crane operator to hold the heavy press in mid-air for a half hour. (c) Al Catalano inserting guideblock into 2000-ton press, watched by Tibor Gasparik, Hisao Kanda, the author, and Manabu Kato. (d) Author with Kawai-type guideblock in USSA-2000 press with Japanese dolls as good-luck charms (gift of Sumitomo company).

Over the next five years, many graduate students and postdocs exploited the new opportunities for research using these high-pressure apparatus (Figure 7d).

One of the first experiments in the USSA-2000 apparatus was conducted by Anne Remsberg who studied the transformation in $\mathrm{Co}_{2} \mathrm{SiO}_{4}$ from the olivine to the spinel phase in collaboration with Jim Boland and Tibor Gasparik; the olivine polymorph is especially colorful (see Figure 7e) and Anne often wore her magenta blouse when presenting talks on her research [20] (see Figure 4b above).

For his Ph.D. research at Stony Brook, Gabriel Gwanmesia adapted the hot-pressing techniques we had developed at the ANU in the 1970s for multi-anvil, high-pressure apparatus [23], in particular the 2000-ton uniaxial split-sphere apparatus (USSA-2000). Subsequently, ultrasonic interferometric techniques were used to measure the sound wave velocities in polycrystalline specimens of the wadsleyite and ringwoodite phases of $\mathrm{Mg}_{2} \mathrm{SiO}_{4}[24,25]$ in the piston-cylinder apparatus at the ANU in collaboration with Sally Rigden and Ian Jackson (Figure 7f,g); later, this Australian collaboration was 
extended to pyrope-majorite garnets by Gwanmesia [26], stishovite by Baosheng Li [27], magnesium ferrite by Sytle Antao [28] and enstatite by Jennifer Kung [29].

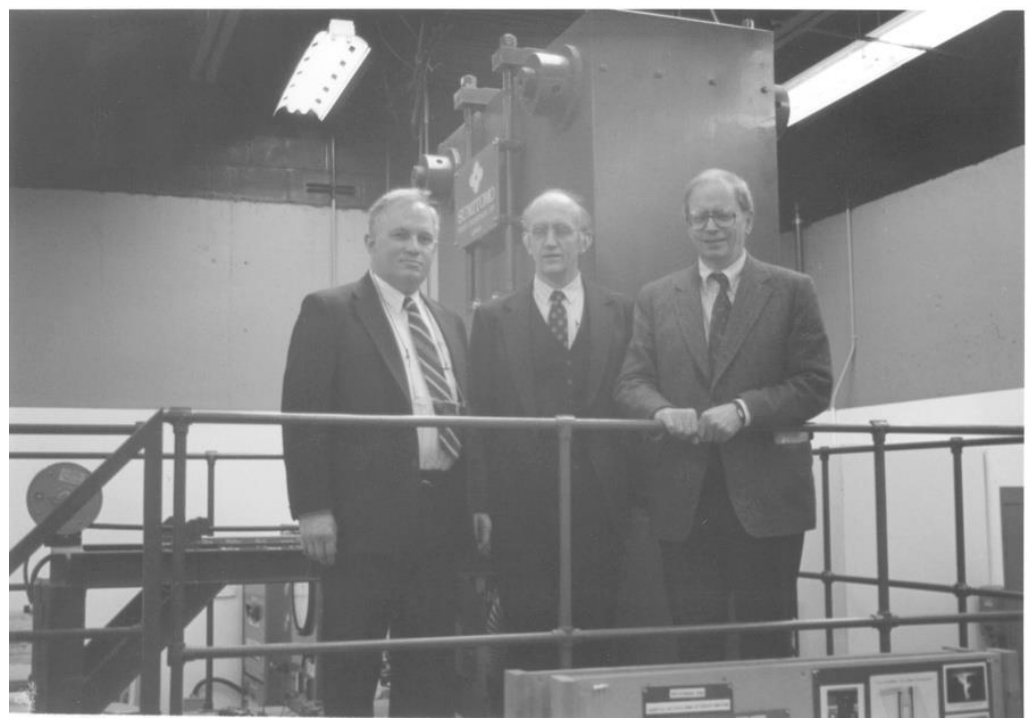

Figure 6. Don Weidner, Bob Liebermann and Charlie Prewitt at dedication ceremony for the USSA-2000 in December 1985.

In 1986, we were awarded a grant from the NSF for "Acquisition and Maintenance of Multi-anvil, High Pressure Apparatus" at Stony Brook. With the financial support for the High-Pressure Lab secured on a continuing basis, the university decided to create a new research unit using funding from the Graduate Research Initiative of the State University of New York. This unit was named the Mineral Physics Institute, with funding to support the operation of the High-Pressure Lab and other research labs in mineral physics and chemistry, and Donald Weidner was appointed as the Founding Director.

In 1986, Charlie Prewitt moved to Washington, D.C. become the Director of the Geophysical Laboratory of the Carnegie Institution of Washington and Alex Navrotsky moved from Arizona State University to Princeton University. These transitions created new opportunities for collaboration. In 1991, a proposal for a NSF Science and Technology Center for High Pressure Research (CHiPR) was funded for a total of 11 years to 2002, with total funding of \$36 million. Stony Brook served as the headquarters of CHiPR with Weidner as the Principal Investigator (PI) and Liebermann as the Co-PI, and branch campuses at Princeton (Co-PI Navrotsky) and Carnegie (Co-PI Prewitt) (Figure 8).

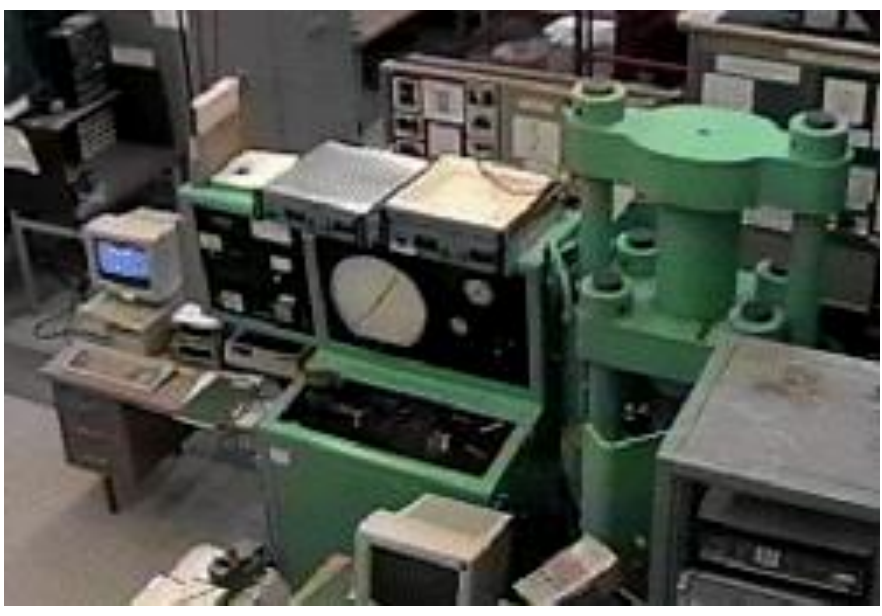

(a)

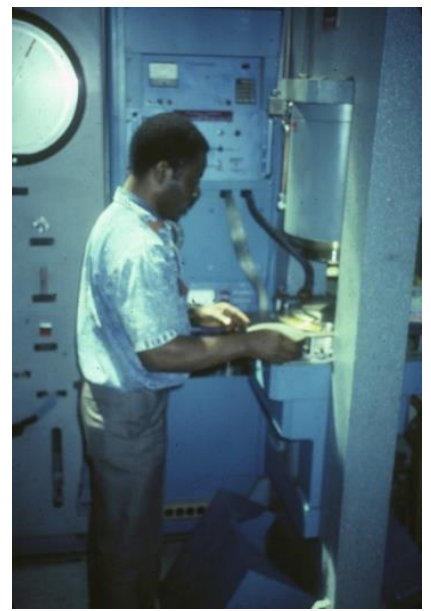

(b)

Figure 7. Cont. 


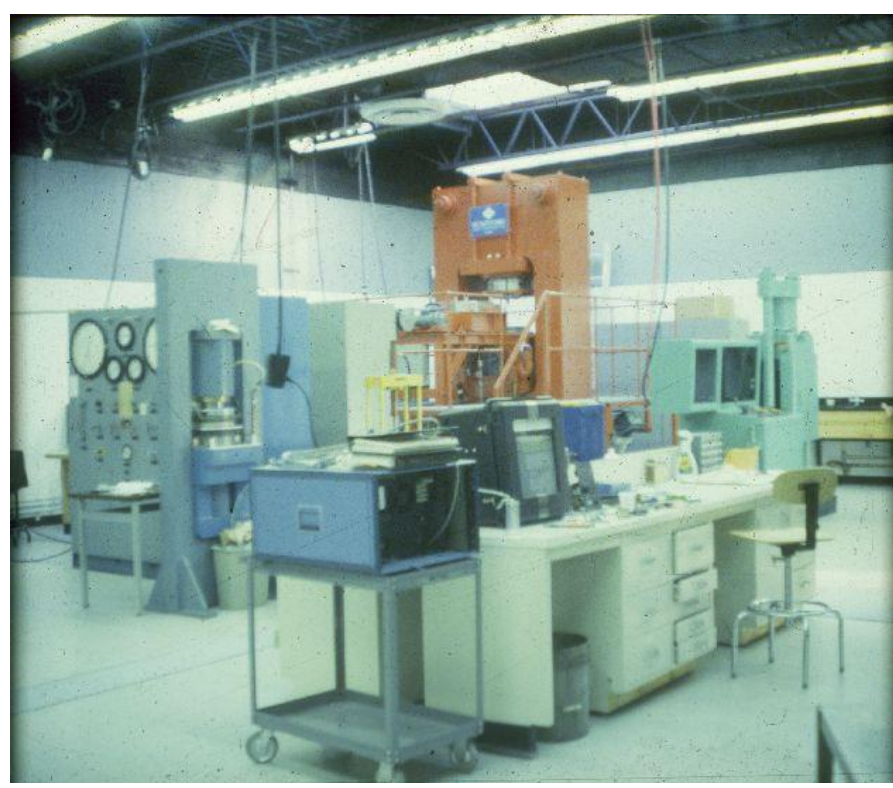

(c)

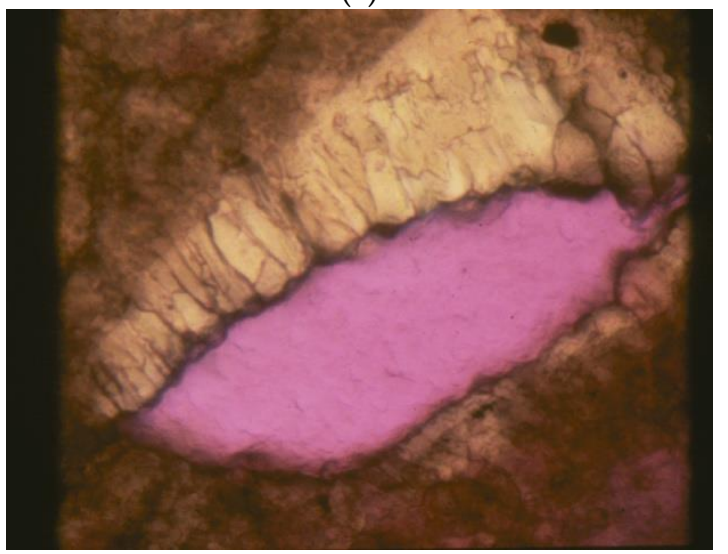

(e)

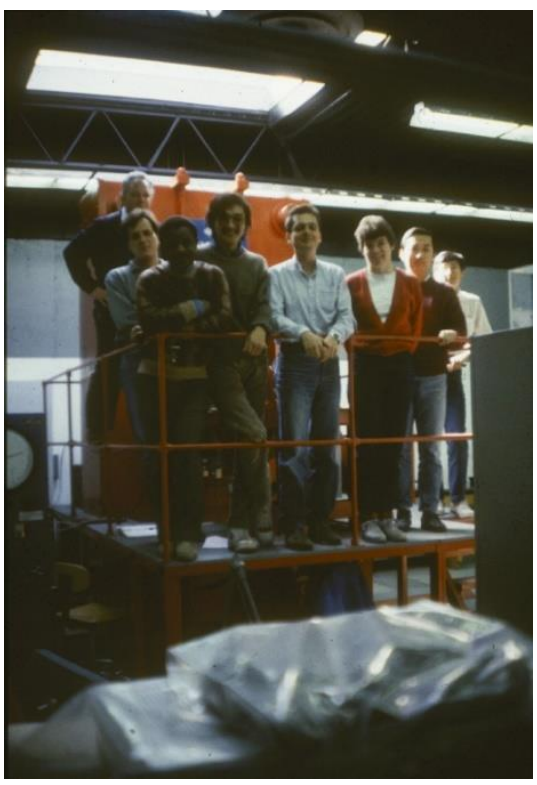

(d)

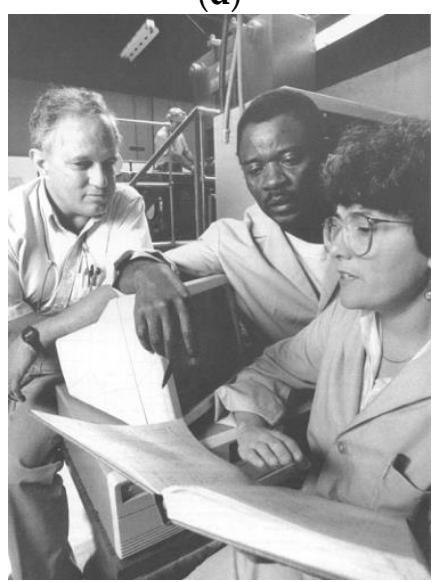

(f)

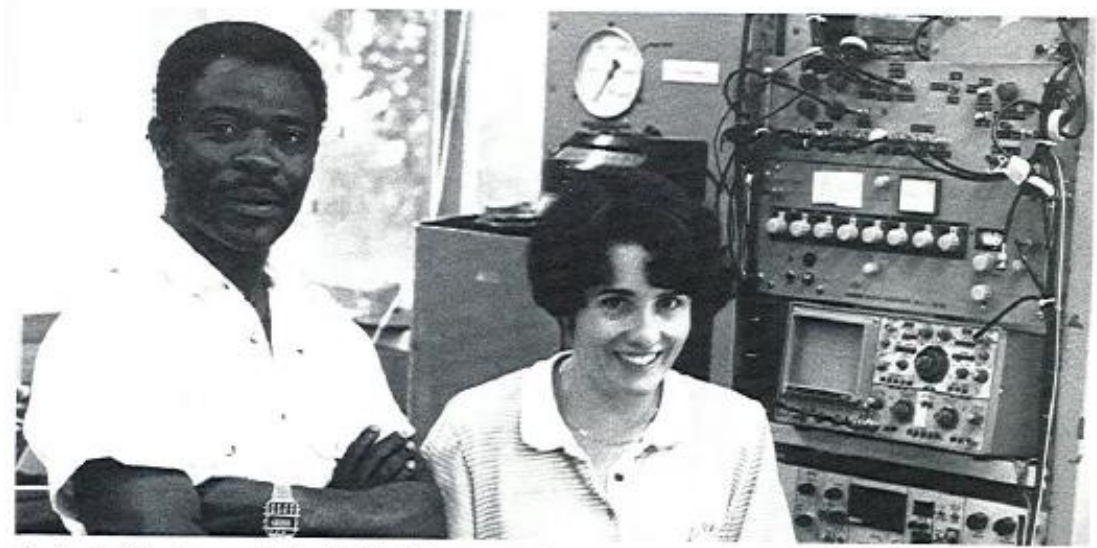

Dr Sally Rigden and Mr Gabriel Gwanmesia with the ullrasonic inlerferometer.

(g)

Figure 7. Stony Brook High Pressure Laboratory circa 1986. (a) 1000-ton Kennedy-Getting press installed in High Pressure Laboratory after inheritance from the laboratory of William LeNoble in the Department of Chemistry. (b) Gabriel Gwanmesia calibrating the girdle-anvil apparatus in the Harwood press as part of his M.S. thesis. (c) The Stony Brook High Pressure Laboratory in 1986 with the USSA-2000, the 500-ton Harwood press with girdle-anvil and the 1000-ton Kennedy-Getting press 
installed and operational. Reproduced with permission from Liebermann [1], published by Elsevier B.V., 2014. (d) Graduate students and postdocs of Bob in High Pressure Lab circa 1988. L. to R. Bob, Yves Bertran (France), Gabriel Gwanmesia (Cameroon), Ren Lu (China), François Guyot (France), Anne Remsberg (USA), Yanbin Wang and Xing Liu (China). Reproduced with permission from Liebermann [1], published by Elsevier B.V., 2014. (e) $\mathrm{Co}_{2} \mathrm{SiO}_{4}$. Residual core of olivine phase (magenta) surrounded by a rim of large golden brown single-crystals of spinel [20]. (f) Sally Rigden from the ANU with Gabriel Gwanmesia and the author in the High-Pressure Lab in 1991. Reproduced with permission from Liebermann [1], published by Elsevier B.V., 2014. (g) Gabriel Gwanmesia and Sally Rigden in Ian Jackson's laboratory at the ANU.

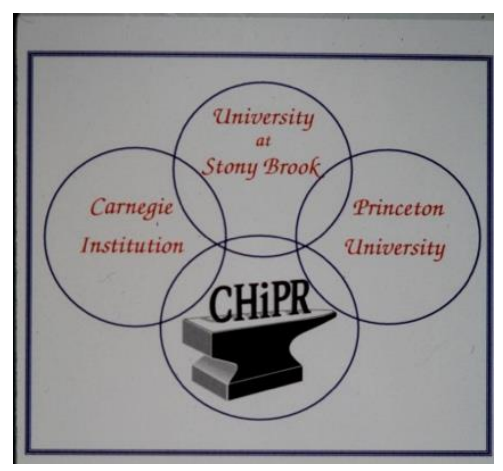

(a)

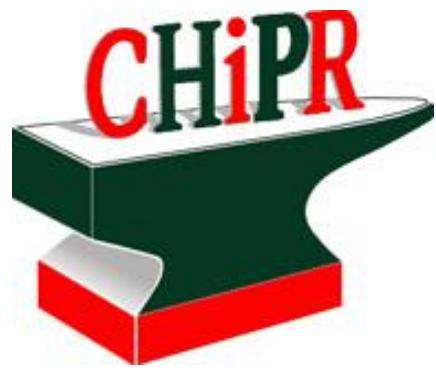

(b)

Figure 8. Founding of CHiPR in 1991. Triumvirate of institutions for CHiPR: Stony Brook University; Carnegie Institution of Washington, and Princeton University and official CHiPR logo (using a blacksmith's anvil as a base). Reproduced with permission from Liebermann [1], published by Elsevier B.V., 2014.

One of the new initiatives in my research group in the CHiPR era began in 1994 when Baosheng $\mathrm{Li}$, then a graduate student and now a Professor in the Department of Geosciences, developed techniques to incorporate ultrasonic interferometric measurements of sound velocities in situ in the Kennedy-Getting high-pressure apparatus in collaboration with Ian Jackson (my first graduate student and subsequently the Director of the Research School of Earth Sciences at the Australian National University; see Figure 9ab). This pioneering development provided the opportunity to conduct sound velocity experiments to pressures of $10 \mathrm{GPa}$ [30] and was exploited over the next few years by many graduate students (Tony Cooke [31], Lucy Flesch [32], Yegor Sinelnikov [33], Jun Liu [34], Kenneth Darling [35]) and postdocs (Ganglin Chen [36], Frédéric Decremps [37,38], Jennifer Kung [39], Gabriel Gwanmesia [40]) for such studies.

At the nearby Brookhaven National Laboratory, the National Synchrotron Light Source (NSLS) was built in the early 1980s. Charlie Prewitt opened our eyes to the research opportunities of such synchrotron X-ray facilities (Figure 10a). In the early 1990s at the beginning of the CHiPR era, Don Weidner and his team moved SAM-85 from the campus to the NSLS and installed it on the superconducting beamline (X17B2). Don recruited Mike Vaughan (Stony Brook Ph.D. 1979) back from the University of Chicago to energize the MPI multi-anvil operation at the NSLS (Figure 10b).

Ultrasonic interferometry was first adapted for use in conjunction with synchrotron X-rays at the X17B2 hutch by my research team (led by Baosheng Li). In a typical experiment with a polycrystalline sample, three types of data are collected: (1) X-ray diffraction from the sample and the pressure standard, (2) ultrasonic waveforms using transfer function method, and (3) X-ray radiographic image of the sample. Data processing of these raw data results in the determination of pressure, unit cell volume, compressional and shear wave velocities at all pressure and temperature $(\mathrm{T})$. Such acoustic experiments have been conducted by many of my students and postdocs over the past 15 years. These 
simultaneous ultrasonic interferometry and X-radiation measurement techniques which we developed at the NSLS [41-43] have now been implemented at many major synchrotron sources in the world, including SPring-8 in Japan, the Advanced Photon Source in the U.S., and DESY in Germany.

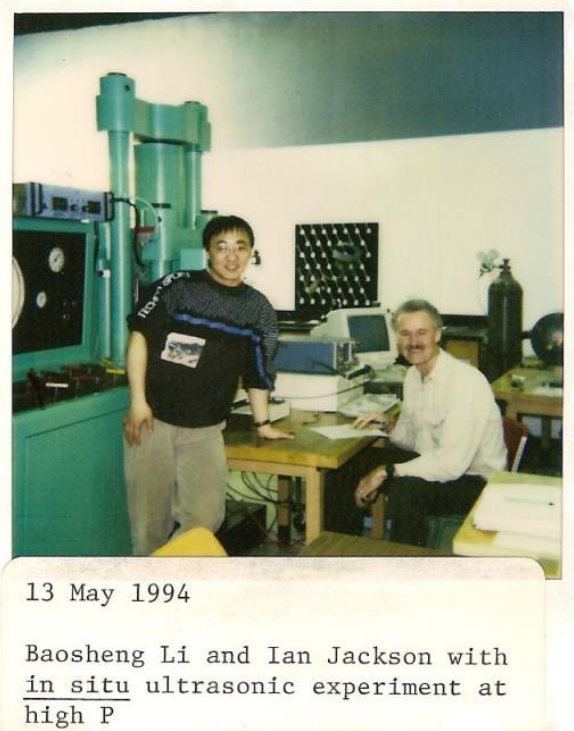

(a)

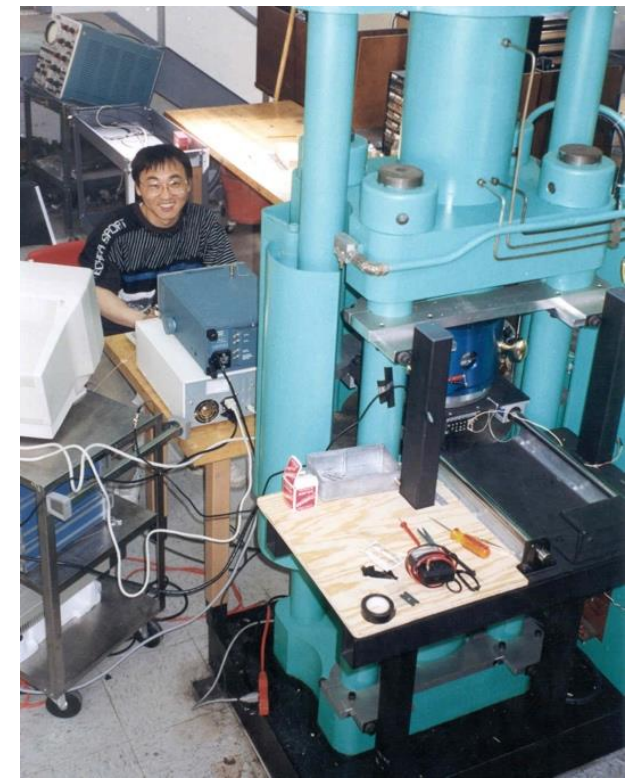

(b)

Figure 9. (a) Baosheng $\mathrm{Li}$ and Ian Jackson using the Kennedy-Getting press to develop their new experiments extending ultrasonic interferometric measurements of sound velocities to $10 \mathrm{GPa}$ in 1994. (b) Baosheng Li and Kennedy-Getting press with Walker-type module in High Pressure Lab in 1994. Reproduced with permission from Liebermann [1], published by Elsevier B.V., 2014.

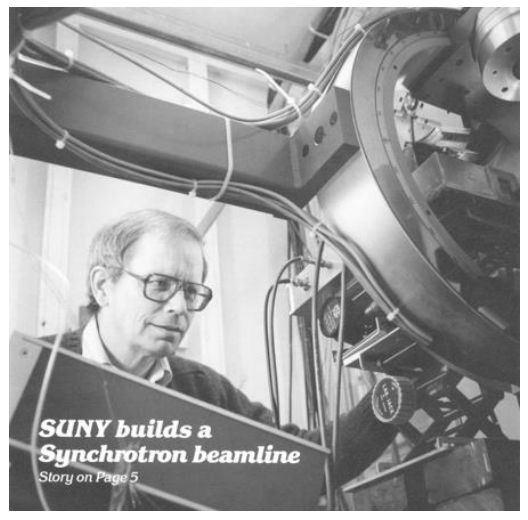

(a)

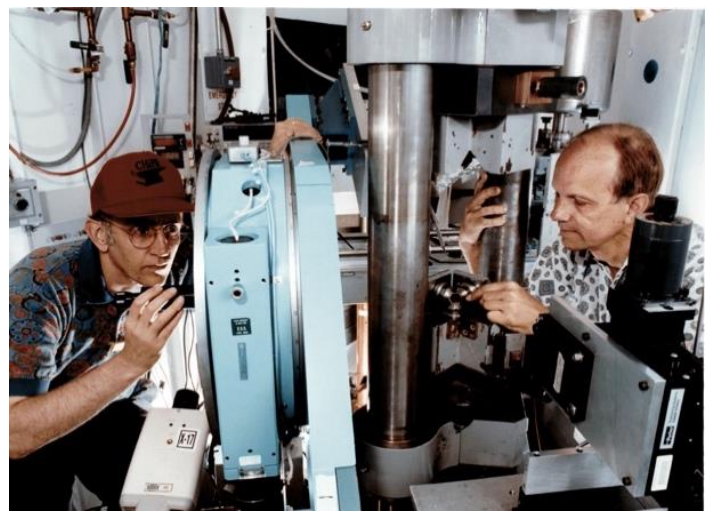

(b)

Figure 10. (a) Charlie Prewitt at X7 beamline of the new NSLS in early 1980s (from newsletter of State University of New York). (b) SAM-85 installed on the superconducting wiggler beamline (X17B2) at NSLS with Don Weidner and Mike Vaughan.

During the first quarter century of my research programs at Stony Brook, we were extremely lucky to have access to the personnel and equipment resources of the departmental machine shop and electronics support facility, which the founding fathers (no women on the faculty in the 1960s) of the Department had wisely incorporated into the staffing plan. The Machine Shop, which originally included Bob Muller in addition to Fred Gwinner and Al Catalano, continued to provide excellent service under Paul Hoversen with Ed Vorisek and Herb Schay and later Carey Koleda and Ricky Palencia. For this entire period, Bill Huebsch and Ben Vitale, who had been recruited from Brookhaven National Lab by the founding Chair Oliver Schaeffer, lent their considerable expertise in all things 
electrical and electronic to our research programs (from major projects such as the High Pressure Lab to the MPI's experimental program at the NSLS to minor needs such as installing antennas on the roof of the Health Sciences Center to receive the signals from our seismic stations on Shelter Island and Lloyd's Neck). These experimental programs simply could not have achieved their national and international stature without the dedicated services provided by these extraordinary staff members. Unfortunately, the Department and the University have recently decided to close these support facilities with the likely consequence that it will be difficult or impossible to establish and maintain such world-class experimental programs in the future.

All of the 25 NSF Science and Technology Centers established in the late 1980s and early 1990s were required to wind-down operations in Year \#10 and close at the end of Year \#12; for CHiPR, this end came in February 2002; at Stony Brook, we marked this occasion with a group photo which we sent as a thank you to Dan Weill, the Program Director for the Instrumentation and Facilities Program in the NSF Division of Earth Sciences (see Figure 11).

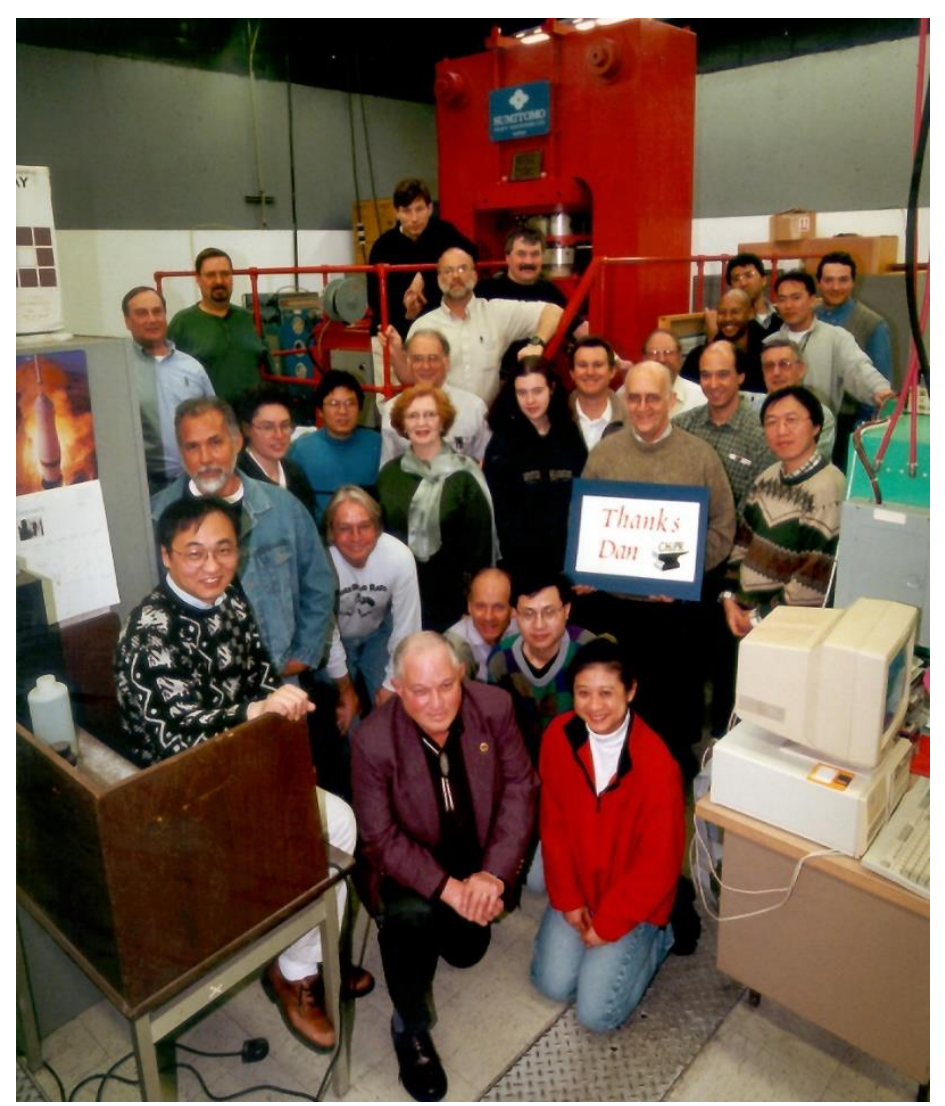

Figure 11. Group photo of faculty, staff and graduate students at Stony Brook in early 2002 as thank you to Dan Weill of the Instrumentation and Facilities Program in Earth Sciences at NSF.

In anticipation of "sunset" of CHiPR, we began to develop ideas for an expanded mineral physics initiative to expand access of high-pressure facilities to broader community, especially for graduate students, postdocs and junior faculty at U.S. academic institutions.

A proposal was submitted in August 2001 on behalf of 18 universities and national laboratories in the U.S. to establish a Consortium for Materials Properties Research in Earth Sciences (COMPRES); funding approved for 5 years commencing in 2002, with Stony Brook University as the headquarters of COMPRES.

COMPRES headquarters subsequently moved to the University of Illinois at Urbana-Chapaign in 2010 and then to the University of New Mexico in 2015. Additional details of the evolution of 
COMPRES may be found in the Bass, Tempe and Long-Range Planning reports (Figure 12a-c); see also [44].

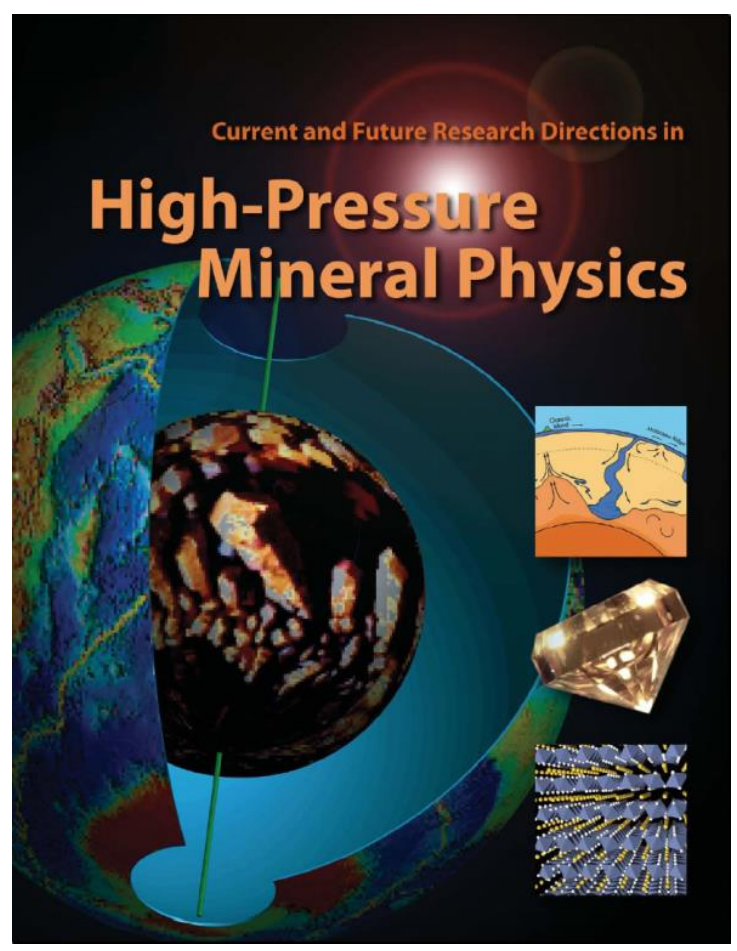

(a)

\section{Understanding the Building Blocks of the Planet}

THE MATERIALS SCIENCE OF EARTH PROCESSES

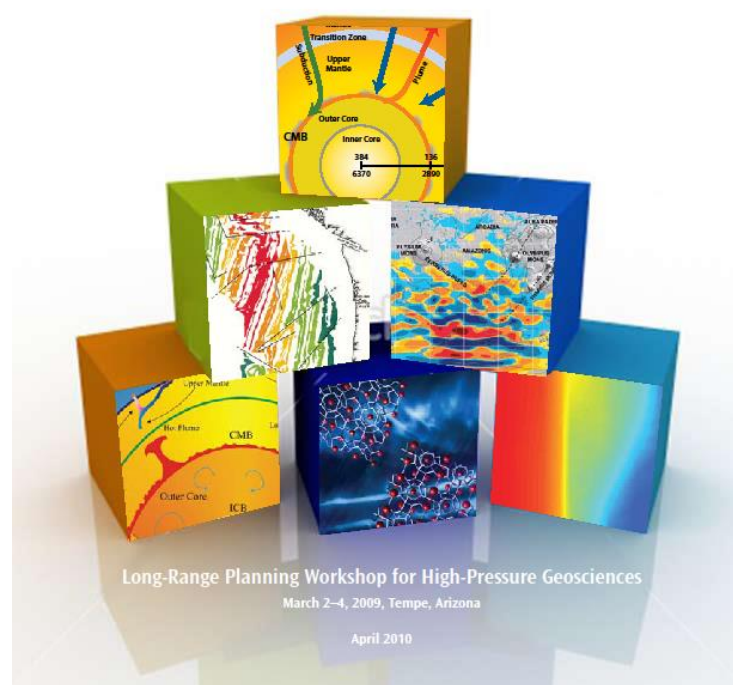

(b)

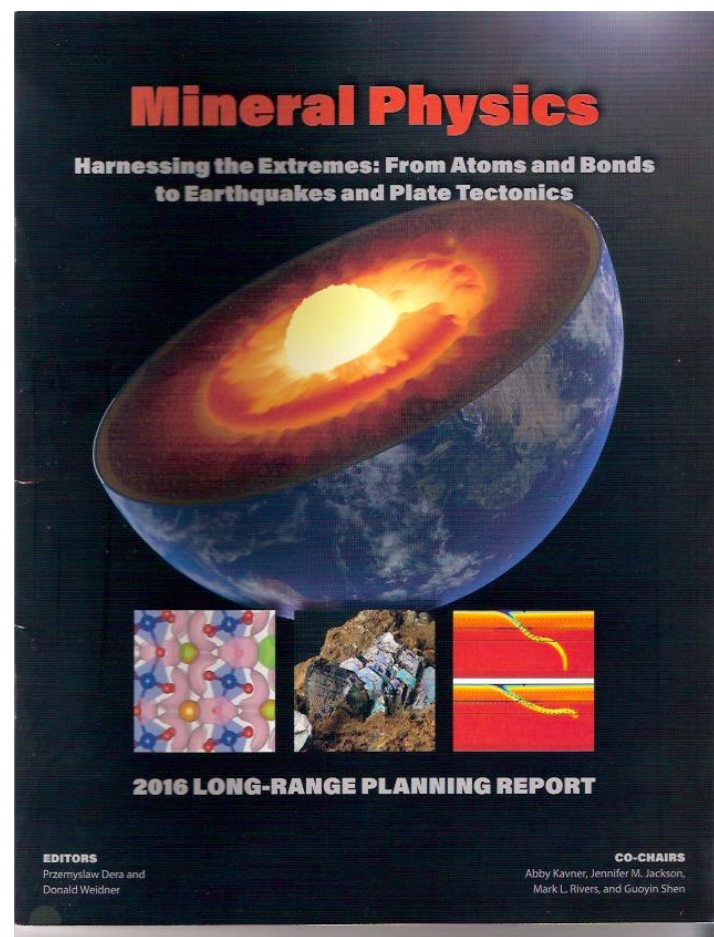

(c)

Figure 12. (a) Frontispiece of Bass Report of COMPRES (edited by Jay Bass, 2004). (b) Frontispiece of Tempe Report of COMPRES (edited by Quentin Williams, 2010). Reproduced with permission from Liebermann [1], published by Elsevier B.V., 2014. (c) Frontispiece of Long Range Planning Report (edited by Przemyslaw Dera and Donald Weidner, 2016). 


\section{Bob as an Administrator at Stony Brook}

My administrative career while at Stony Brook has been characterized by a series of serendipitous events; each of these has involved finding something good or useful to do even though I was not specifically looking for it.

The first of these events occurred in 1982-1983: I had been encouraged to apply for a position as Program Director for Geophysics in EAR at the NSF. I decided not to apply as I was under consideration for Chair of the Department of Earth and Space Sciences; when the Astronomy faculty vetoed my appointment as Chair, I was free to go on sabbatical leave to France in September 1983 to work with Jaoul and Poirier and their colleagues in Orsay and Paris (see above).

After a 3-month stay in Japan, which included the "shopping trip" describe above, I became the Director of the new High-Pressure Laboratory and later the Co-Director of CHiPR (1991). In 1993, I was a candidate to become the Director of the Research School of Earth Sciences at the Australian National University; however, I withdrew my candidacy after a receiving a generous retention offer from Stony Brook organized by Don Lindsley and Don Weidner.

In 1997, I became Chair of the newly-named Department of Geosciences and found that to be one of the most rewarding administrative experiences of my life; we hired new faculty (including Lianxing Wen and Troy Rasbury), recruited many outstanding graduate students and expanded our research programs.

When Paul Armstrong (Dean of the College of Arts and Sciences) departed for Brown University in 2000, Provost Robert McGrath asked me to serve as Interim Dean. I did so with every intention of only staying a year or so but became somewhat addicted to the challenges of the College leadership and so applied for the permanent job. When I was not chosen to be the new Dean, I decided to take another sabbatical in France, and was fortunate that Olivier Jaoul and his team had now moved to the Université Paul Sabatier in southern France (see Figure 13), where I spent another sabbatical leave in 2002-2003.

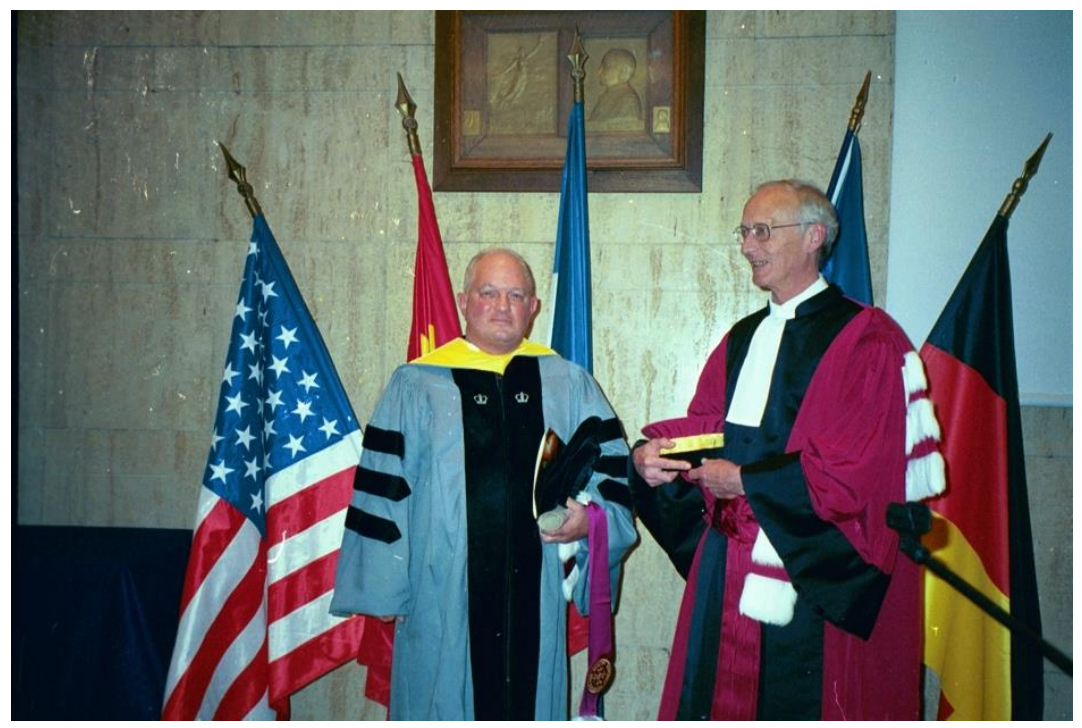

Figure 13. Author receiving degree of Docteur Honoris Causa at Université Paul Sabatier from Olivier Jaoul in 2004. Reproduced with permission from Liebermann [1], published by Elsevier B.V., 2014.

On my return to Stony Brook in 2003, I assumed the role of President of COMPRES and held that position until 2010. I then "retired" from administrative duties and returned to teaching at the graduate level (GEO 556 and 607) and helping to advise two groups of graduate students: (a) Three African-American women who were pursuing M.S. degrees in Geosciences Instrumentation under the supervision of Lars Ehm (Associate Professor in the Department of Geosciences) with the objective of qualifying for positions as Science Associates at the national laboratories of the U.S. Department of 
Energy (such as Brookhaven National Lab) [45]; (b) Three Chinese women who were working with my colleague Baosheng Li (Professor in the Department of Geosciences) on projects to utilize ultrasonic interferometry in conjunction with synchrotron X-radiation to measure sound velocities of minerals at high pressures and temperatures [46-48]. All six of these graduate students took my Solid-State Geophysics course in the Fall 2013 semester (see Figure 14), which was my last semester of teaching at Stony Brook as I formally retired in 2014 and was then appointed as a Research Professor in the Department of Geosciences and the Mineral Physics Institute.

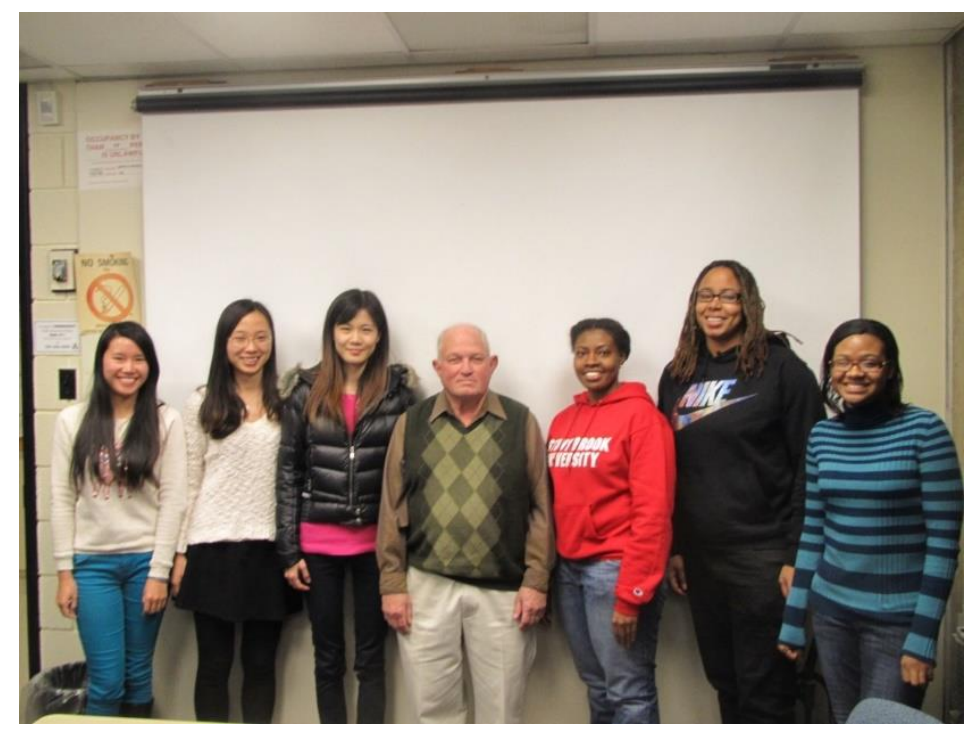

Figure 14. Graduate students in GEO 556: Solid-State Geophysics in Fall 2013 semester, with Bob teaching his last class at Stony Brook. Left to right: Xintong Qi, Ting Chen, Xuebing Wang, Bob, Adairé Heady, Ashley Thompson, Melissa Sims.

\section{For Additional Details}

Liebermann, R.C. Bob-san and High Pressure Science and Technology in Japan: A 40+-Year History. Rev. High Press. Sci. Technol. 2011, 21, 115-126.

Liebermann, R.C. Multi-anvil, high-pressure apparatus: A half century of development and progress. High Press. Res. 2011, 31, 493-532.

Liebermann, R.C.; Prewitt, C.T. From Airlie House in 1977 to Lake Morey in 2007: 30 Years of evolution of mineral physics. Phys. Earth Planet. Inter. 2014, 228, 36-45.

Liebermann, R.C. The Role of Serendipity in My Career in Mineral Physics: 1968 to 2013. Phys. Earth Planet. Inter. 2014, 228, 307-323.

Liebermann, R.C. History of Japan-US/High Pressure Mineral Physics Seminars: 1976 to 2012. Phys. Earth Planet. Inter. 2014, 233, 1-35.

Funding: This paper was written with support from a research grant to Baosheng Li and the author from the National Science Foundation (EAR-1524078).

Acknowledgments: I owe an enormous debt to many colleagues and friends for their support and collaboration over the past 43 years at Stony Brook, in addition to the graduate students and postdoctoral associates and visiting scientists cited above. In particular, I wish to express my appreciation and thanks to Don Weidner, Charlie Prewitt, John Parise Lars Ehm and Baosheng Li on the faculty of the Department of Geosciences and Michael Vaughan, Jiuhua Chen, and Jianzhong Zhang on the research faculty of the MPI.

Conflicts of Interest: The author declares no conflict of interest. 


\section{Appendix A}

Appendix A.1 GEO 556: Solid-State Geophysics (Originally ESS 556)

From the Spring 1977 to Fall 2013 semesters, Bob has taught this course 14 times and had the privilege of introducing the following graduate students and postdocs to the wonders of mineral physics (some of whom audited the course and others who took it twice!).

Sp77: Doug Anderson, Elizabeth Hauser, and Robin Reichlin

-listed as GEO 607.

Audits: Alan Kafka, Hubert King, Louise Levien, Michael Vaughan.

Sp78: Jay Bass, Ben Burton, Paula Davidson, Barbara Leitner, Susan Narbut.

First time listed as ESS 556.

F79: Andy Au, Jay Bass, Ben Burton, Ann Singer.

F82: Hwai-kuo Chen, John Kandelin, Tom Ruubel, Michael Simpson, Ann Sirinides.

Sp85: Gabriel Gwanmesia, Virginia Haniford, Jaidong Ko, Xing Liu, Amir Yeganeh-haeri, Jianzhong Zhang.

F87: Ren Lu, George Moussouris, Rosemary Pacalo, Kim Pacanovsky, Anne Remsberg, Yanbin Wang.

Audit: Gabriel Gwanmesia.

F89: Yves Bertran, Yuan Liu, Yue Meng, Woosun Yang, Yusheng Zhao.

F91: Jishan Jin, Baosheng Li, Wenlu Zhu, Yong Zou.

F93: Reggie Minault, Bingming Shen-tu, Yegor Sinelnikov, Xiang Xia.

F95: Tony Cooke, Lucy Flesch, Rui Li, Jun Liu, Yujin Wu, Hui Zhao.

Audit: Frédéric Béjina.

F97: Corne Kreemer, Haibin Su

Audits: Ganglin Chen, Jiuhua Chen, Hiroki Kagi, Jianzhong Zhang.

SP00: Stan Adler, Kenneth Darling, Elliot Klein, Li Li, Laura Rossier, Veronika Vajdova

F11: Yu Chen, Yuan-yuan Liu, Guangrui.Qian, Gina Scherbenko, Terry-Ann Suer.

Audit: Matt Jacobsen.

F13: Ting Chen, Adairè Heady, Xintong Qi, Ashley Thompson, Melissa Sims, XuebingWang.

Audits: Xuefei Li, Yongtao Zou.

Appendix A.2 Theses Supervised by Bob Liebermann at ANU and SBU

Appendix A.2.1 Australian National University—Research School of Earth Sciences

Ian Jackson (1976)—Ph.D.

Subject: Phase equilibria and elastic properties in silicate analogue systems: studies of melting and polymorphic phase transformations.

Leonie Jones (1976)—Ph.D.

Subject: High-temperature elastic properties of fluoride and oxide analogues.

State University of New York at Stony Brook:

Department of Earth and Space Sciences (1976-1997)

Department of Geosciences (1997-2019)

Barbara J. Leitner (1979)—M.S.

Subject: Elasticity of Single Crystal Pyrope

Ellyn A. Schlesinger (1979)-M.S. 
Subject: A Seismic Noise Survey of Long Island, New York

Susan M. Narbut (1979)-M.S.

Subject: Phase equilibria of the disproportionation reaction $\mathrm{Ca}_{2} \mathrm{SnO}_{4}$ (strontium plumbate) $\mathrm{CaSnO}_{3}$ (perovskite) plus $\mathrm{CaO}$ (rocksalt)

Peter J. Lellis (1980)—B.S. Honors

Subject: Isostructural systematics of elasticity in silicate minerals

Ann E. Sirinides (1983)-M.S.

Subject: Elastic Properties of two-phase Aggregates

Richard J. Wilkinson (1983)-M.S.

Subject: The Long Island Sound Earthquake of October 21, 1981: Location, Focal Mechanism, Intensity Survey

Thomas Ruubel (1984)-M.S.

Subject: Laboratory measurements of velocities in rocks from the Ramapo fault system

Kirk Maasch (1986)—B.S. Honors

Subject: Acoustic and static compression experiments on the elastic behavior of hematite.

Gabriel Gwanmesia (1987)-M.S.

Subject: Pressure calibration in a girdle-anvil and a DIA-type pressure apparatus at room temperature $\left(25^{\circ} \mathrm{C}\right)$ and high temperature $\left(1000^{\circ} \mathrm{C}\right)$

Appendix A.2.2 Theses Supervised (cont.)

Anne R. Remsberg (1990)—Ph.D.

Subject: A study of the polymorphic phase transformations in $\mathrm{Co}_{2} \mathrm{SiO}_{4}$

Ren Lu (1990)-M.S.

Subject: Study of kinetic rates of transformation between garnet and perovskite phases of $\mathrm{CaGeO}_{3}$

Yanbin Wang (1991)—Ph.D

Subject: Electron microscopy and X-ray diffraction studies on structural phase transitions in $\mathrm{MgSiO}_{3}$ perovskite.

Gabriel Gwanmesia (1991)—Ph.D

Subject: High pressure elasticity for the beta and spinel polymorphs of $\mathrm{Mg}_{2} \mathrm{SiO}_{4}$ and composition of the transition zone of the Earth's mantle.

Appendix A.2.3 Yves Bertran at Université Paris XI [Olivier Jaoul]

Baosheng Li (1993)-M.S.

Subject: Polycrystalline Stishovite: Hot-pressing and elastic properties

Baosheng Li (1996)—Ph.D.

Subject: Ultrasonic Measurements of the Elastic Wave Velocities of Olivine and Beta Polymorphs of $\mathrm{Mg}_{2} \mathrm{SiO}_{4}$ at Mantle Transition Zone P and T and Geophysical Implications

Lucy C. Flesch (1997)-M.S.

Subject: Sound velocities in polycrystalline $\mathrm{MgSiO}_{3}$-orthopyroxene to $10 \mathrm{GPa}$ at room temperature Jun Liu (1997)-M.S. 
Subject: Calorimetry study of the coesite-stishovite transformation and calculation of the phase boundary

Yegor Sinelnikov (1997)-M.S.

Subject: Elasticity of $\mathrm{CaTiO}_{3}-\mathrm{CaSiO}_{3}$ perovskites

Joseph A. Cooke (1997)—M.S.

Subject: Ultrasonic measurements of the elastic wave velocities of $\mathrm{Mg}_{3} \mathrm{Al}_{2} \mathrm{Si}_{3} \mathrm{O}_{12}$ pyrope garnet to 9 GPa at room temperature

Yegor Sinelnikov (1998)—Ph.D.—Check This Date?

Subject: Elasticity of $\mathrm{MgSiO}_{3}$-perovskite at high pressure and temperature by ultrasonic interferometry

Appendix A.2.4 Theses Supervised (cont.)

Jun Liu (2001)—Ph.D.

Subject: Elasticity of Pyrope-Majorite Garnets at High Pressures and Temperatures and Implications for Geophysics

Kenneth Darling (2002)-M.S.

Subject: Ultrasonic Measurements of the Elastic Wave Velocities of Polycrystalline (Mg,Fe) San Carlos Olivine

\section{References}

1. Liebermann, R.C. The Role of Serendipity in My Career in Mineral Physics: 1968 to 2013. Phys. Earth Planet. Inter. 2014, 228, 307-323. [CrossRef]

2. Anderson, O.L. Equations of State of Solids for Geophysics and Ceramic Science; Oxford University Press: Oxford, UK, 1995.

3. Weidner, D.J.; Carleton, H.R. Elasticity of coesite. J. Geophys. Res. 1997, 82, 1334-1346. [CrossRef]

4. Bass, J.D.; Liebermann, R.C.; Weidner, D.J.; Finch, S.J. Elastic properties from acoustic and volume compression experiments. Phys. Earth Planet. Inter. 1981, 25, 140-158. [CrossRef]

5. Leitner, B.J.; Weidner, D.J.; Liebermann, R.C. Elasticity of single crystal pyrope and implications for garnet solid solution series. Phys. Earth Planet. Inter. 1980, 22, 111-121. [CrossRef]

6. Sasaki, S.; Prewitt, C.T.; Liebermann, R.C. The crystal structure of $\mathrm{CaGeO} 3$ perovskite and the crystal chemistry of the GdFeO3-type perovskites. Am. Mineral. 1983, 68, 89-98.

7. Poirier, J.P.; Liebermann, R.C. On the activation volume for creep and its variation with depth in the Earth's lower mantle. Phys. Earth Planet. Inter. 1984, 35, 283-293. [CrossRef]

8. Liebermann, R.C.; Maasch, A.K. Acoustic and static compression experiments on the elastic behavior of hematite. J. Geophys. Res. 1986, 91, 4651-4656. [CrossRef]

9. Liebermann, R.C. Impact of technology on high-pressure geophysics. In The Impact of Technology on Geophysics; a study conducted by the Impact of Technology Panel of the Geophysics Study Committee of the Geophysics Research Board; National Research Council, National Academy of Sciences: Washington, DC, USA, 1979.

10. Houlier, B.; Jaoul, O.; Abel, F.; Liebermann, R.C. Oxygen and silicon self-diffusion in natural olivine at $\mathrm{T}=1300^{\circ} \mathrm{C}$. Phys. Earth Planet. Inter. 1988, 50, 240-250. [CrossRef]

11. Bertran-Alvarez, Y.; Jaoul, O.; Liebermann, R.C. Fe-Mg interdiffusion in single crystal olivines at very high pressure and controlled oxygen fugacity: Technological advances and initial data at 7 GPa. Phys. Earth Planet. Inter. 1992, 70, 102-118. [CrossRef]

12. Jaoul, O.; Bertran-Alvarez, Y.; Liebermann, R.C.; Price, G.D. Fe-Mg interdiffusion in olivine up to 9 GPa at T $=600-900{ }^{\circ} \mathrm{C}$. Experimental data and comparison with defect calculations. Phys. Earth Planet. Inter. 1995, 89, 199-218. [CrossRef]

13. Raterron, P.; Bejina, F.; Doukhan, J.C.; Jaoul, O.; Liebermann, R.C. Olivine/Fe-metal equilibrium under high pressure: An ATEM investigation. Phys. Chem. Miner. 1998, 25, 285-493. [CrossRef]

14. Béjina, F.; Raterron, P.; Zhang, J.; Jaoul, O.; Liebermann, R.C. Activation volume of silicon diffusion in San Carlos olivine. Geophys. Res. Lett. 1997, 24, 2597-2600. [CrossRef] 
15. Béjina, F.; Jaoul, O.; Liebermann, R.C. Activation volume for Si diffusion in San Carlos olivine: Implications for upper mantle rheology. J. Geophys. Res. 1999, 104, 25529-25542. [CrossRef]

16. Ingrin, J.; Liebermann, R.C. Deviatoric stress in a girdle-anvil type high pressure apparatus: Effect on the quartz-coesite phase transformation. Phys. Earth Planet. Inter. 1989, 54, 378-385. [CrossRef]

17. Wang, Y.; Liebermann, R.C.; Boland, J.N. Olivine as an in situ piezometer in high pressure apparatus. Phys. Chem. Miner. 1988, 15, 493-497. [CrossRef]

18. Guyot, F.; Gwanmesia, G.D.; Liebermann, R.C. An olivine to beta phase transformation mechanism in Mg2SiO4. Geophys. Res. Lett. 1991, 18, 89-92. [CrossRef]

19. Martinez, I.; Wang, Y.; Guyot, F.; Liebermann, R.C.; Doukhan, J.-C. Microstructures and iron partitioning in $(\mathrm{Mg}, \mathrm{Fe}) \mathrm{SiO} 3$ perovskite-( $\mathrm{Mg}, \mathrm{Fe}) \mathrm{O}$ Magnesiowustite assemblages: An analytical transmission electron microscopy study. J. Geophys Res. 1997, 102, 5265-5280. [CrossRef]

20. Remsberg, A.R.; Boland, J.N.; Gasparik, T.; Liebermann, R.C. Mechanism of the olivine-spinel transformation in $\mathrm{Co}_{2} \mathrm{SiO}_{4}$. Phys. Chem. Miner. 1988, 15, 498-506. [CrossRef]

21. Wang, Y.; Guyot, F.; Liebermann, R.C. Electron microscopy of (Mg,Fe)SiO 3 perovskite: Evidence of structural phase transitions and implications for the lower mantle. J. Geophys. Res. 1992, 97, 12327-12347. [CrossRef]

22. Gwanmesia, G.D.; Liebermann, R.C. Polycrystals of high-pressure phases of mantle minerals: Hot-pressing and characterization of physical properties. In High Pressure Research: Applications to Earth and Planetary Sciences; Syono, Y., Manghnani, M.H., Eds.; Terra Scientific Publishing Co., Tokyo/American Geophysical Union: Washington, DC, USA, 1992; pp. 117-135.

23. Gwanmesia, G.D.; Li, B.; Liebermann, R.C. Hot pressing of polycrystals of high pressure phases of mantle minerals in multi-anvil apparatus. PAGEOPH 1993, 141, 467-484. [CrossRef]

24. Gwanmesia, G.D.; Rigden, S.; Jackson, I.; Liebermann, R.C. Pressure dependence of elastic wave velocity for $\beta-\mathrm{Mg}_{2} \mathrm{SiO}_{4}$ and the composition of the Earth's mantle. Science 1990, 250, 794-797. [CrossRef]

25. Rigden, S.M.; Gwanmesia, G.D.; FitzGerald, J.D.; Jackson, I.; Liebermann, R.C. Spinel elasticity and seismic structure of the transition zone of the mantle. Nature 1991, 354, 143-145. [CrossRef]

26. Rigden, S.M.; Gwanmesia, G.D.; Liebermann, R.C. Elastic wave velocities of a pyrope-majorite garnet to 3 GPa. Phys. Earth Planet. Inter. 1994, 84, 35-44. [CrossRef]

27. Li, B.; Rigden, S.M.; Liebermann, R.C. Elasticity of stishovite at high pressure. Phys. Earth Planet. Inter. 1996, 96, 113-127. [CrossRef]

28. Antao, S.M.; Jackson, I.; Li, B.; Kung, J.; Chen, J.; Hassan, I.; Liebermann, R.C.; Parise, J.B. High-temperature elasticity of magnesioferrite spinel. Phys. Chem. Miner. 2007, 34, 345-350. [CrossRef]

29. Kung, J.; Jackson, I.; Liebermann, R.C. High-temperature elasticity of polycrystalline orthoenstatite $\left(\mathrm{MgSiO}_{3}\right)$. Am. Mineral. 2011, 96, 577-585. [CrossRef]

30. Li, B.; Jackson, I.; Gasparik, T.; Liebermann, R.C. Elastic wave velocity measurement in multi-anvil apparatus to 110 GPa using ultrasonic interferometry. Phys. Earth Planet. Inter. 1996, 98, 79-91. [CrossRef]

31. Chen, G.; Cooke, J.A., Jr.; Gwanmesia, G.D.; Liebermann, R.C. Elastic Wave Velocities of $\mathrm{Mg}_{3} \mathrm{Al}_{2} \mathrm{Si}_{3} \mathrm{O}_{12}-\mathrm{Pyrope}$ Garnet to 10 GPa. Am. Mineral. 1999, 84, 384-388. [CrossRef]

32. Flesch, L.C.; Li, B.; Liebermann, R.C. Sound velocities in polycrystalline $\mathrm{MgSiO}_{3}$-orthopyroxene to $10 \mathrm{GPa}$ at room temperature. Am. Mineral. 1998, 83, 444-450. [CrossRef]

33. Sinelnikov, Y.D.; Chen, G.; Neuville, D.R.; Liebermann, R.C. Ultrasonic shear velocities of $\mathrm{MgSiO}_{3}$-perovskite at high pressure and temperature and lower mantle composition. Science 1998, 281, 677-679. [CrossRef]

34. Liu, J.; Chen, G.; Gwanmesia, G.D.; Liebermann, R.C. Elastic wave velocities of pyrope-majorite garnets $\left(\mathrm{Py}_{62} \mathrm{Mj}_{38}\right.$ and $\left.\mathrm{Py}_{50} \mathrm{Mj}_{50}\right)$ to $9 \mathrm{GPa}$. Phys. Earth Planet. Inter. 2000, 120, 153-163. [CrossRef]

35. Darling, K.L.; Gwanmesia, G.D.; Kung, J.; Li, B.; Liebermann, R.C. Ultrasonic measurements of the sound velocities in polycrystalline San Carlos olivine in multi-anvil, high-pressure apparatus. Phys. Earth Planet. Inter. 2004, 143-144, 19-31. [CrossRef]

36. Chen, G.; Li, B.; Liebermann, R.C. Selected elastic moduli of single crystal olivines from ultrasonic experiments to mantle pressures. Science 1996, 272, 979-980. [CrossRef] [PubMed]

37. Decremps, F.; Li, B.; Liebermann, R.C. Single-crystal elasticity of $\mathrm{ZnO}$ at high pressure. In Proceedings of the International Conference on High Pressure Science and Technology (AIRAPT-17), Honolulu, HI, USA, 25-30 July 1999; Volume 2, pp. 810-813.

38. Decremps, F.; Zhang, J.; Li, B.; Liebermann, R.C. Pressure-induced softening of shear modes in ZnO. Phys. Rev. B 2001, 63, 224105. [CrossRef] 
39. Kung, J.; Li, B.; Weidner, D.J.; Zhang, J.; Liebermann, R.C. Elasticity of $\left(\mathrm{Mg}_{0.83} \mathrm{Fe}_{0.17}\right) \mathrm{O}$ ferropericlase at high pressure: Ultrasonic measurements in conjunction with X-radiation techniques. Earth Planet. Sci. Lett. 2002, 203, 557-566. [CrossRef]

40. Gwanmesia, G.D.; Zhang, J.; Darling, K.; Kung, J.; Li, B.; Wang, L.; Neuville, D.; Liebermann, R.C. Elasticity of polycrystalline pyrope $\left(\mathrm{Mg}_{3} \mathrm{Al}_{2} \mathrm{Si}_{3} \mathrm{O}_{12}\right)$ to $9 \mathrm{GPa}$ and $1000{ }^{\circ} \mathrm{C}$. Phys Earth Planet. Inter. 2006, 155, 179-190. [CrossRef]

41. Liebermann, R.C.; Chen, G.; Li, B.; Gwanmesia, G.D.; Chen, J.; Vaughan, M.T.; Weidner, D.J. Sound Velocity Measurements in Oxides and Silicates at Simulatneous High Pressures and Temperatures using Ultrasonic Techniques in Multi-Anvil Apparatus in Conjunction with Synchrotron X-radiation Determination of Equation of State. Rev. High Press. Sci. Technol. 1998, 7, 75-78. [CrossRef]

42. Li, B.; Liebermann, R.C. Indoor seismology by probing the Earth's interior by using sound velocity measurements at high pressures and temperatures. Proc. Natl. Acad. Sci. USA 2007, 104, 9145-9150. [CrossRef]

43. Li, B.; Liebermann, R.C. Study of the Earth's interior using measurements of sound velocities in minerals by ultrasonic interferometry. Phys. Earth Planet. Inter. 2014, 233, 135-153. [CrossRef]

44. Liebermann, R.C.; Prewitt, C.T. From Airlie House in 1977 to Lake Morey in 2007: 30 Years of evolution of mineral physics. Phys. Earth Planet. Inter. 2014, 228, 36-45. [CrossRef]

45. Liebermann, R.C.; Ehm, L.; Gwanmesia, G.D. Creating career paths for African-American students in Geosciences. EOS Earth Space Sci. News 2016, 97, 9-11. [CrossRef]

46. Chen, T.; Gwanmesia, G.D.; Wang, X.; Zou, Y.; Liebermann, R.C.; Michaut, C.; Li, B. Anomalous elastic properties of coesite at high pressure and implications for the upper mantle X-discontinuity. Earth Planet. Sci. Lett. 2015, 412, 42-51. [CrossRef]

47. Wang, X.; Chen, T.; Qi, X.; Zou, Y.; Kung, J.; Yu, T.; Wang, Y.; Liebermann, R.C.; Li, B. Acoustic travel time gauges for in-situ determination of pressure and temperature in multi-anvil apparatus. J. Appl. Phys. 2015, 118, 065901. [CrossRef]

48. Chen, T.; Liebermann, R.C.; Zou, Y.; Li, Y.; Qi, X.; Li, B. Tracking silica in Earth's upper mantle using new sound velocity data for coesite to 5.8 GPa and 1073K. Geophys. Res. Lett. 2017, 44, 7757-7765. [CrossRef]

(C) 2019 by the author. Licensee MDPI, Basel, Switzerland. This article is an open access article distributed under the terms and conditions of the Creative Commons Attribution (CC BY) license (http://creativecommons.org/licenses/by/4.0/). 